\title{
Distribution of barnacle epizoites of the crab Portunus pelagicus in the Moreton Bay region, eastern Australia
}

\author{
Shane W. Gaddes ${ }^{\mathrm{A}, \mathrm{B}, \mathrm{C}}$ and Wayne D. Sumpton ${ }^{\mathrm{A}}$ \\ ${ }^{A}$ Department of Primary Industries, Agency of Food and Fibre Sciences, Southern Fisheries Centre, \\ PO Box 76, Deception Bay, Qld 4508, Australia. \\ ${ }^{B}$ Present address: Queensland Fisheries Service, GPO Box 46, Brisbane, Qld 4001, Australia. \\ ${ }^{\mathrm{C}}$ Corresponding author. Email: shane.gaddes@dpi.qld.gov.au
}

\begin{abstract}
The parasites of some decapod crustaceans are known to cause sterilisation of their hosts, and can thus have an important impact on the population dynamics of infested species. Blue swimmer crabs (Portunus pelagicus) collected in three areas around Moreton Bay, Australia were examined for the presence of epizoic barnacles in their branchial chambers and on their carapace. Of the 952 crabs inspected $92 \%$ were infested with Octolasmis spp. The mean number of barnacles (predominantly Octolasmis warwickii) per carapace and gill chamber (mainly O. angulata) were 2.35 and 71.1, respectively. Barnacle infestation of gills was found to differ significantly by area, season and sex with the deeper offshore areas exhibiting the highest number of barnacles. The distribution within the hosts showed barnacles were more likely to be distributed in areas closer to the inhalant aperture. Highest abundances were found on the proximal surface of the hypobranchial side of gills 3, 4 and 5. Host moult stage and parasitism by Sacculina granifera were also found to affect the abundance of epizoic barnacles in some areas.
\end{abstract}

Extra keywords: blue swimmer crab, Octolasmis spp., parasites, Portunidae.

\section{Introduction}

The blue swimmer crab, Portunus pelagicus, is widely distributed throughout the Indo-West Pacific region where it contributes to important commercial and recreational fisheries. Valuable fisheries for the blue swimmer crab exist in all mainland Australian states, with the commercial fishery in Queensland taking between 500 and 700 tonnes annually, predominantly from southern waters around Moreton Bay (Sumpton et al. 2000).

Due to its economic importance, there have been several studies on the parasites and epizoites of $P$. pelagicus in Moreton Bay. These studies have concentrated mainly on infestation by the rhizocephalan barnacle Sacculina granifera Boschma (Thomson 1951; Phillips and Cannon 1978; Bishop and Cannon 1979; Weng 1987; Shields and Wood 1993; Sumpton et al. 1994a), which is known to cause sterilisation and thus have a detrimental impact on fishery production. The occurrence of barnacle epizoites of the genus Octolasmis and Chelonibia patula (Ranzani) within Moreton Bay have been recorded by Phillips and Cannon (1978) and Shields (1992), although the biological and ecological implications of infestation were not described. Jeffries et al. (1982) recorded five species from the genus Octolasmis on P. pelagicus from the seas adjacent to Singapore and at least two species (Octolasmis angulata and Octolasmis warwickii) are known to settle on P. pelagicus within Moreton Bay (G. Walker, personal communication).

Lepadomorph barnacles of the genus Octolasmis are frequently found attached to many decapod crustaceans (Jeffries and Voris 1996). The cypris larvae of Octolasmis spp. attach themselves to the exoskeleton of the host, metamorphose into juveniles that grow rapidly by filter feeding on particulate matter transported through the host's ventilatory system (Gannon 1990). As adults they are permanently attached to the host with the life-cycle of the barnacle governed by the host's intermoult period (Jeffries and Voris 1996). Reproductive success is dependent upon the barnacle reaching maturity before the host moults. Thus to achieve reproductive success, a cypris larva must select a host with an intermoult period that provides sufficient time for the larva to attach, metamorphose to the adult form, oviposit and release nauplii (Jeffries et al. 1992).

The epizoic relationship between barnacles of the genus Octolasmis and the commercially important North American portunid Callinectes sapidus has received much attention (Walker 1974; Jeffries and Voris 1983; Gannon 1990; Gannon and Wheatly 1992; Gannon and Wheatly 1995; Jeffries and Voris 1996; Key et al. 1997). Gannon and Wheatly (1992) noted that excess epizoic load may represent a potential threat to crab populations through obstruction of the ventilatory 
current and decreased ventilatory effectiveness, leading to high mortality in stressed crabs. A similar situation may also exist for P. pelagicus since it shares many common attributes with the blue crab C. sapidus, including life history, habitat, commercial importance and epizoites. Without an understanding of the spatial and temporal prevalence of Octolasmis spp. it is impossible to determine the magnitude of any impact of the epizoite on $P$. pelagicus populations.

This study examines the spatial and temporal patterns of the barnacle epizoites of $P$. pelagicus, with particular emphasis on Octolasmis spp.

\section{Materials and methods}

Blue swimmer crabs were collected mainly using baited commercial crab pots in three areas from the Moreton Bay region in Queensland, Australia (Fig. 1). Only male crabs with a carapace width $<15 \mathrm{~cm}$ and female crabs were available because males $>15 \mathrm{~cm}$ were retained for sale by the commercial fishers. A sample of $\sim 40$ male and 40 female crabs was collected from each area during a 14-day period in the months of January, April, July and October 1999 representing four seasonal samples. The winter sample from the north Moreton Bay area was obtained using commercial prawn trawl gear since there were no commercial fishers using pots in that area at that time. The crabs were kept on ice and frozen when they reached the laboratory. All crabs were sexed and adult females were further classified as ovigerous or non-ovigerous. Crabs were classified as adult if the abdominal flap was not firmly attached to the thorax (Van Engel 1958). The carapace width, taken between the notch of the eighth and ninth anterolateral spines, was measured to the nearest millimetre. The dorsal and ventral surfaces of all crabs were examined for barnacles with the number of each species recorded. Barnacles that settled on other appendages were not counted or analysed due to the geographic and temporal variation of limb autonomy in portunid crabs (Smith and Hines 1991). Parasitism of crabs by the rhizocephalan Sacculina granifera was staged according to the methodology of Sumpton et al. (1994a).

All crabs were dissected and visually inspected for gill barnacles. Preliminary examinations yielded comparable densities in both gill chambers so one branchial chamber was selected at random for each crab. Settlement sites were recorded with respect to gill chamber (left or right), aspect (hyperbranchial or hypobranchial), gill number $(1=$ posterior to $8=$ anterior) and area on the gills (proximal or distal). Settlement was also recorded on the epipodites of the three pairs of maxillipeds (hypobranchial gill rake, epibranchial gill rake and scaphognathite) and the inner wall of the branchial chamber.

The time involved in identifying to species level the large numbers of Octolasmis spp. found in the branchial chambers of crabs (up to 914 per crab) necessitated a compromise in terms of taxonomic accuracy. Positive identifications of $O$. angulata were commonly made, but as each individual Octolasmis spp. was not identified the precise species composition was not determined beyond the generic level. Barnacles of the genus Octolasmis were visually examined and split into two arbitrary groups, those that were 'recently settled', were translucent and less than $\sim 1.5 \mathrm{~mm}$ from the base of the carina to the tip of the tergum. The second group contained the 'adult' octolasmids that were generally pink and greater than $\sim 1.5 \mathrm{~mm}$ from the base of the carina to the tip of the tergum.

Each crab was moult staged according to the setagenic methodology developed by Drach (1939) and modified by Lyle and MacDonald (1983; Table 1). This involved the classification of the excised distal half of the epipodite of the first maxilliped, which was mounted in water on glass slides.

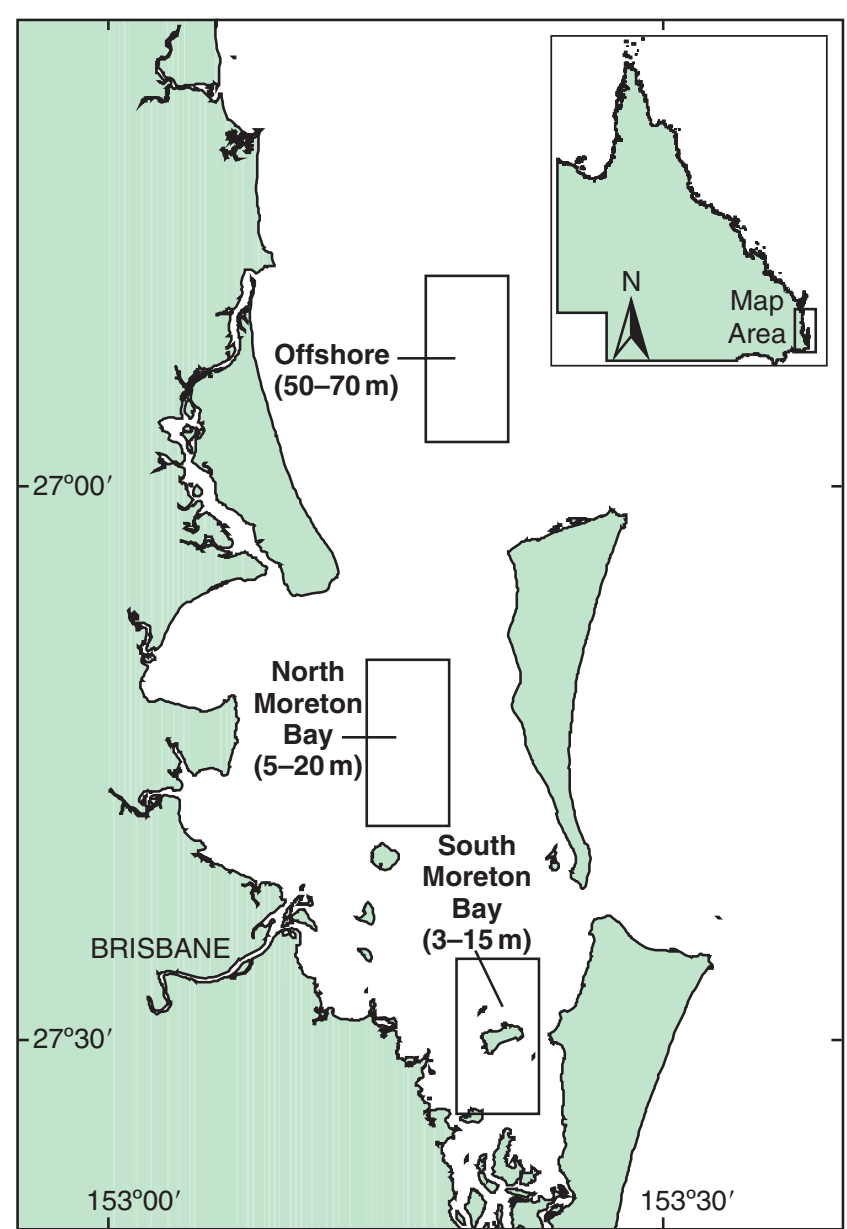

Fig. 1. Map of study region showing areas where crabs were sampled.

Table 1. Moult stages used in setagenic methodology (Lyle and MacDonald 1983)

\begin{tabular}{llll}
\hline Moult stage & $\begin{array}{l}\text { Macro } \\
\text { stage }\end{array}$ & $\begin{array}{l}\text { Micro } \\
\text { stage }\end{array}$ & General description \\
\hline $\begin{array}{l}\text { Post-moult } \\
\text { Intermoult }\end{array}$ & AB & - & $\begin{array}{l}\text { Exoskeleton soft and pliable } \\
\text { Exoskeleton hard, no retraction } \\
\text { of epidermis }\end{array}$ \\
Premoult & D & D0 & $\begin{array}{l}\text { Slight epidermal retraction } \\
\text { Epidermal retraction, new setae } \\
\text { forming } \\
\text { Epidermal retraction, setae formed, } \\
\text { barbules forming } \\
\text { Epidermal retraction, new setae } \\
\text { fully developed with barbules }\end{array}$ \\
& D1 &
\end{tabular}

Spatial, temporal and sexual trends in Octolsamis spp. infestation of intermoult crabs was analysed by generalised linear models (GLM) fitted to the natural $\operatorname{logarithm}[\ln (x+c)$ where $c=$ smallest count $\times 2^{-1}$ ] of Octolasmis spp. abundances. Carapace width was used as a covariate to standardise the effects of differing crab sizes between 
treatments. Means presented are predicted means from the GLM based on a standardised carapace width. All means were bias-corrected and back transformed using the method outlined by Kendall et al. (1983):

$$
y=\exp ^{\left[x+(n-1) S^{2} / 2 n\right]-c}
$$

where $y=$ bias-corrected, back transformed mean; $x=$ natural logtransformed mean; $n=$ error degrees of freedom; $S^{2}=$ variance (residual mean square); $c=$ constant from $\ln (x+c), 0.5$ in this case.

\section{Results}

Distribution of Octolasmis spp. within host branchial chambers

A total of 952 crabs were collected, 472 females and 480 males. The females consisted of $85(18 \%)$ ovigerous and $387(81.4 \%)$ non-ovigerous, with three $(0.6 \%)$ immature. Of the males, $475(99 \%)$ were mature with five (1\%) immature. The carapace width of sampled crabs ranged from 80 to 159 $\mathrm{mm}$ for females and 78 to $137 \mathrm{~mm}$ for males. The width of male crabs was artificially truncated at $\sim 137 \mathrm{~mm}$ carapace width as this size corresponds with the minimum legal size. The crabs exhibited a $92 \%$ overall prevalence of Octolasmis spp. Infestation was sampled across all size classes (Fig. 2). Prevalence of Octolasmis spp. ranged up to 914 barnacles per gill chamber, but $90 \%$ of crabs had a barnacle abundance of between one and 200 barnacles per gill chamber.

\section{Distribution of Octolasmis spp. on the gills}

A total of 77273 Octolasmis spp. individuals were found inside the branchial chambers of the sampled crabs, $73.7 \%$ on the gills, $23.3 \%$ on the branchial chamber under the gills and the remaining $3 \%$ on other surfaces within the branchial chamber. Only barnacles settling on the surfaces of the gills and the branchial chamber under the gills were further analysed in this study. There was no significant difference $(P>0.05)$ in the distribution of Octolasmis spp. under the gills compared to those on the gills (Fig. 3) with gill 6 having the highest settlement $(27.6 \%)$. The area for each gill was calculated using the formula for a cone $(A=\pi r h)$ with Octolasmis spp. abundance per gill found to be independent of gill area $\left(\chi^{2}=36748.1\right.$, d.f. $\left.=5, P<0.0001\right)$. Barnacles were found to be significantly more abundant on the hypobranchial side of gills than the hyperbranchial side $(F=2343.7$, d.f. $=3807, P<0.001$; Table 2$)$. The proximal surfaces of the gills also displayed a significantly higher prevalence of Octolasmis spp. $(F=66.1$, d.f. $=3807$, $P<0.001$ ) with $70.3 \%$ found on the proximal surfaces of the gills and only $29.7 \%$ on the distal surfaces.

The symbiotic barnacle, Chelonibia patula was found on the external surfaces of the carapace of $360(37.8 \%)$ crabs. The occurrence of $C$. patula was strongly associated with the presence of Octolasmis spp. in the branchial chambers $\left(\chi^{2}=32.784\right.$, d.f. $\left.=1, P<0.0001\right)$. The occurrence of $O$. warwickii on external surfaces was also tested for independence with other Octolasmis species in the branchial

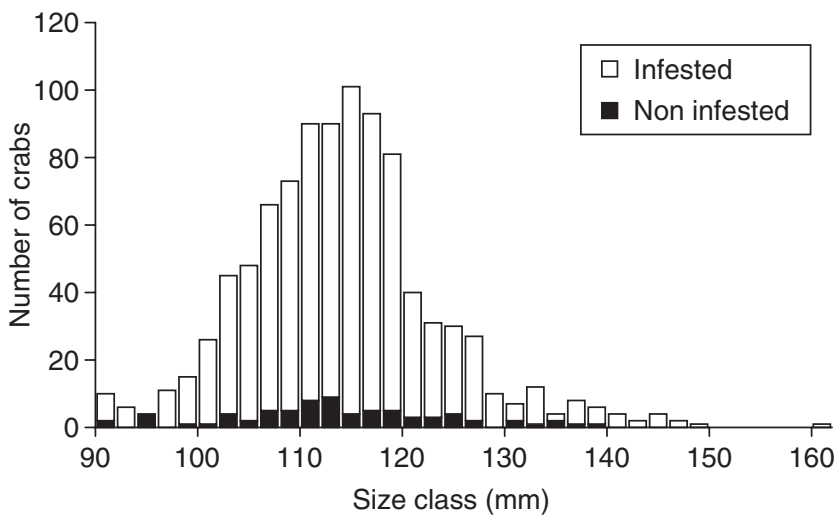

Fig. 2. Carapace width frequency of Portunus pelagicus infested with barnacle epizoites (Octolasmis spp.) compared with non-infested crabs.

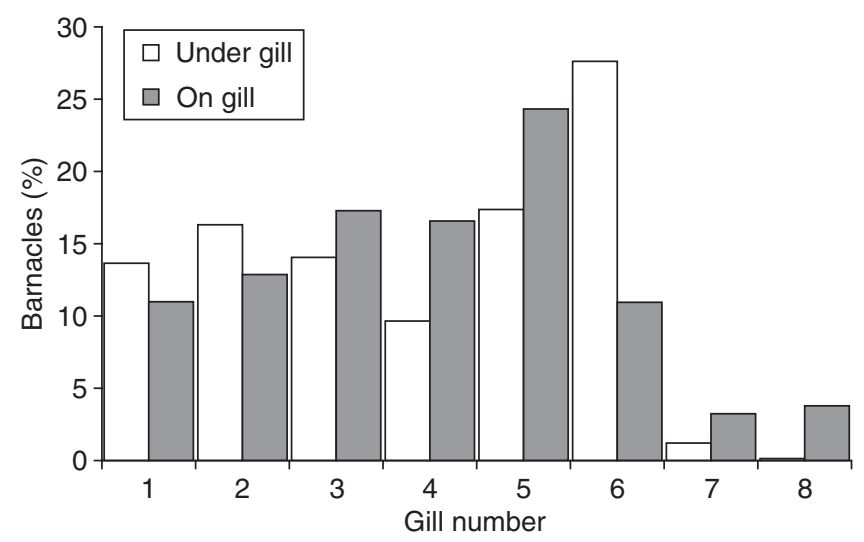

Fig. 3. Percentage of total number of Octolasmis spp. settling on and under each of the gills $(n=952)$. Gills numbered using the scheme of Walker (1974).

Table 2. Percentage of Octolasmis spp. found on surfaces of the gills of infested Portunus pelagicus

\begin{tabular}{lccc}
\hline & Proximal & Distal & Total \\
\hline Hyperbranchial & $1223(2.4 \%)$ & $1189(2.3 \%)$ & $2412(4.7 \%)$ \\
Hypobranchial & $34806(67.9 \%)$ & $14045(27.4 \%)$ & $48851(95.3 \%)$ \\
Total & $36029(70.3 \%)$ & $15234(29.7 \%)$ & $51263(100 \%)$ \\
\hline
\end{tabular}

chambers and also found to be dependent $\left(\chi^{2}=29.442\right.$, d.f. $=1, P<0.0001)$. In contrast the chi-squared test for independence of the infestation of $C$. patula and $O$. warwickii showed that these species were independent $\left(\chi^{2}=3.738\right.$, d.f. $=1, P=0.053)$.

\section{Effect of crab moult condition on infestation by barnacle epizoites}

Moult condition appeared to have an effect on the abundance of barnacles, however, the low number of crabs captured in the 


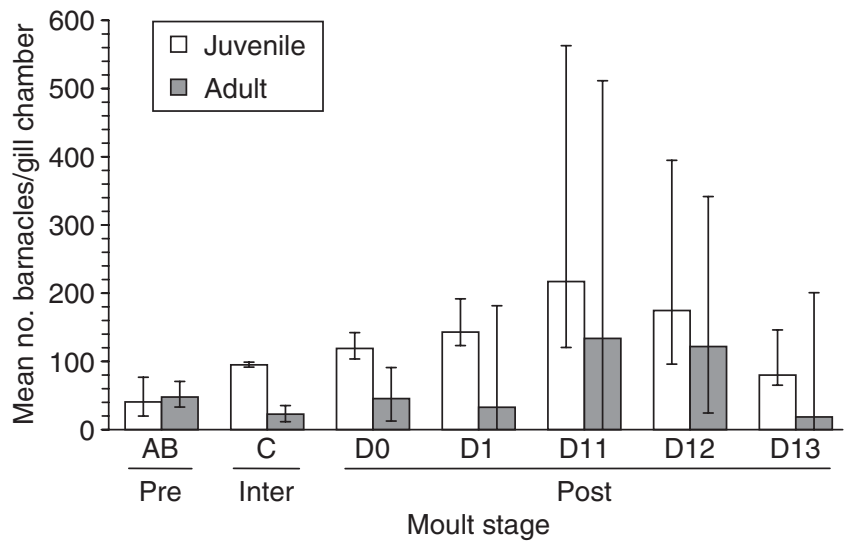

Fig. 4. Prevalence ( \pm s.e.m.) of juvenile and adult Octolasmis spp. in gill chambers of Portunus pelagicus at various moult stages. $\mathrm{AB}$, premoult; C, intermoult; D0-D13, five substages of post-moult.

premoult (D0 to D13) condition resulted in inflated variances and an inability to detect differences. This is most probably due to the low catchability of crabs during ecdysis (Sumpton et al. 1994b). Figure 4 shows significantly higher abundances of juvenile Octolasmis spp. in the branchial chambers of post-moult crabs $(73.3 \pm 28)$, compared with crabs in the intermoult condition $(36.5 \pm 5)$. In contrast, adult Octolasmis spp. were not as abundant in post-moult crabs than in intermoult crabs, with $12.9 \pm 6$ and $27.1 \pm 2$ barnacles per gill chamber, respectively.

\section{Spatial, temporal and sexual variation in barnacle infestation}

Crabs in the intermoult stage and crabs not parasitised by Sacculina granifera were analysed further using a GLM to identify any differences in infestation between areas, across seasons and between sexes. The model analysing the effect of various factors on the prevalence of 'recently settled' Octolasmis spp. in host gill chambers accounted for $69.8 \%$ of the variation in barnacle abundance (Table 3). All factors and second order interactions significantly affected mean barnacle abundance $(P<0.05)$. The covariate was also highly significant $(P<0.001)$ with a positive relationship between carapace width and barnacle prevalence.

The offshore area was marked by significantly higher predicted mean barnacle abundances for all seasons, with the highest mean abundance of 166.7 (95\%C.I. 202.8-137.0) barnacles per gill chamber occurring in summer (Fig. 5). North and south Moreton Bay showed high inter-seasonal variation, with mean abundances varying between 0.3 (95\%C.I. 0.4-0.2) for north Moreton Bay in winter and 30.4 (95\%C.I. 45.2-20.5) for south Moreton Bay in autumn. The north Moreton Bay sample for winter was significantly lower than all other seasons and areas $(P>0.05)$, although this sample was obtained using trawl gear rather than baited pots.
Table 3. Results of a generalised linear model analysing the effect of various factors on the prevalence of 'recently settled' Octolasmis spp.

\begin{tabular}{lrrrrc}
\hline Factor & d.f. & \multicolumn{1}{c}{ s.s. } & \multicolumn{1}{c}{ m.s. } & \multicolumn{1}{c}{ v.r. } & $F$ \\
\hline Area & 2 & 1808.273 & 904.136 & 621.22 & $<0.001$ \\
Season & 3 & 278.982 & 92.994 & 63.89 & $<0.001$ \\
Sex & 1 & 6.878 & 6.878 & 4.73 & 0.03 \\
Area $\times$ season & 6 & 119.539 & 19.923 & 13.69 & $<0.001$ \\
Area $\times$ sex & 2 & 9.108 & 4.554 & 3.13 & 0.044 \\
Season $\times$ sex & 3 & 15.470 & 5.157 & 3.54 & 0.014 \\
Area $\times$ season $\times$ & 6 & 17.151 & 2.859 & 1.96 & 0.069 \\
$\quad$ sex & 1 & 18.661 & 18.661 & 12.82 & $<0.001$ \\
$\quad$ Carapace width & 1 & & & & \\
$\quad$ covariate) & 643 & 935.835 & 1.455 & & \\
Residual & 667 & 3209.895 & 4.812 & & \\
Total & & & & & \\
\hline
\end{tabular}

d.f., Degrees of freedom; m.s., mean square; s.s., sum of squares; v.r., variance ratio.

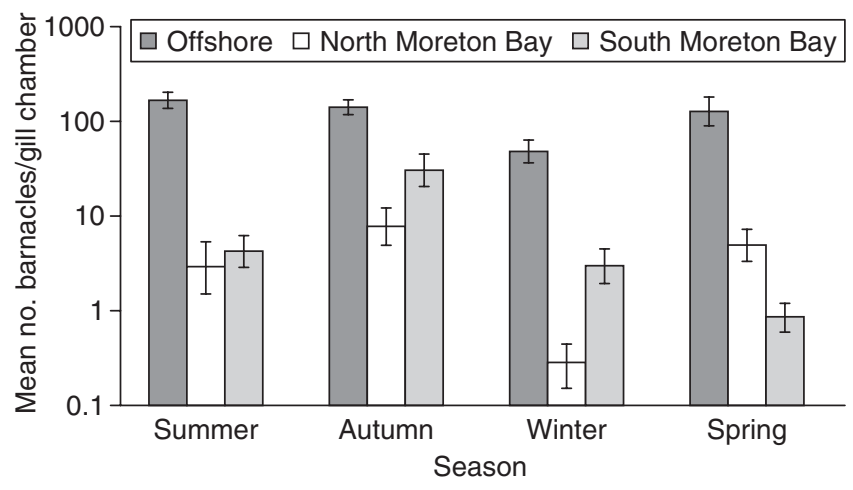

Fig. 5. Seasonal variation in model predictions ( \pm s.e.m.) of 'recently settled' Octolasmis spp. prevalence in gill chambers of Portunus pelagicus from three areas.

Barnacle prevalence in gill chambers of male and female crabs in the offshore area was significantly higher $(P<0.001)$ than all other areas, with 119.4 (95\%C.I. 145.797.9) and 145.3 (95\%C.I. 119.4-108.8) barnacles per gill chamber, respectively (Fig. $6 a$ ). South Moreton Bay was the only area where the epizoite prevalence between sexes was significantly different. The mean predicted barnacle abundances of recently settled Octolasmis spp. in gill chambers by season and sex are shown in Fig. 6b. Crabs sampled during summer and autumn had significantly higher barnacle loads than those sampled in winter. Differences between sexes were not significant $(P>0.05)$ within any one season.

The analysis of variance table from the GLM for adult octolasmids is displayed in Table 4. This model only accounted for $19.6 \%$ of the variation in barnacle abundance. Sex was the only factor that did not significantly account for variation in barnacle abundances, with all other factors and interactions significant at the $5 \%$ level. The covariate was 

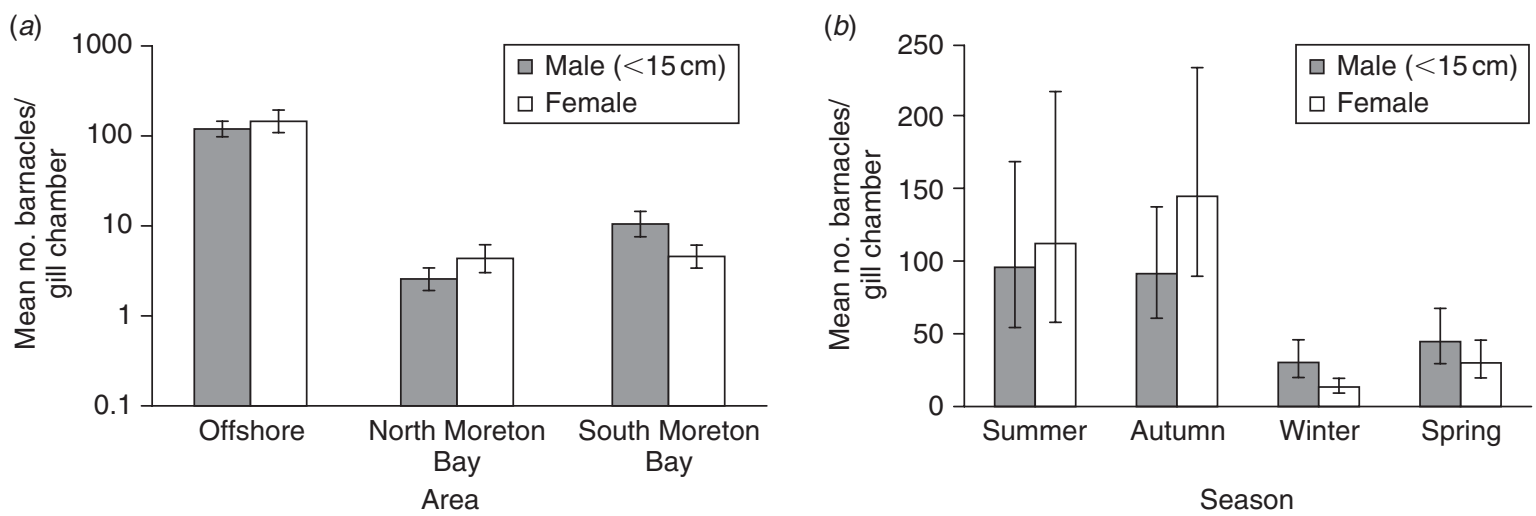

Fig. 6. Model predictions ( \pm s.e.m.) of the (a) spatial and (b) temporal variation in recently settled Octolasmis spp. prevalence on male and female Portunus pelagicus in the three areas.

Table 4. Results of a generalised linear model analysing the effect of various factors on the prevalence of 'adult' Octolasmis spp.

\begin{tabular}{lcrrrr}
\hline & d.f. & \multicolumn{1}{c}{ s.s. } & m.s. & v.r. & \multicolumn{1}{c}{$F$} \\
\hline Area & 2 & 40.198 & 20.099 & 8.81 & $<0.001$ \\
Season & 3 & 55.093 & 18.364 & 8.05 & $<0.001$ \\
Sex & 1 & 3.236 & 3.236 & 1.42 & 0.234 \\
Area $\times$ season & 6 & 253.836 & 42.306 & 18.55 & $<0.001$ \\
Area $\times$ sex & 2 & 32.193 & 16.097 & 7.06 & $<0.001$ \\
Season $\times$ sex & 3 & 44.2 & 14.733 & 6.46 & $<0.001$ \\
Area $\times$ season $\times$ & 6 & 55.04 & 9.173 & 4.02 & $<0.001$ \\
$\quad$ sex & & & & & \\
Carapace width & 1 & 10.383 & 10.383 & 4.55 & 0.033 \\
$\quad$ (covariate) & & & & & \\
Residual & 643 & 1466.286 & 2.28 & & \\
Total & 667 & 1960.465 & 2.939 & & \\
\hline
\end{tabular}

d.f., Degrees of freedom; m.s., mean square; s.s., sum of squares; v.r., variance ratio.

also significant with a positive relationship between carapace width and barnacle abundance $(P<0.001)$.

There was a high degree of variation in adult barnacle abundance for both sexes by season and area (Fig. 7). Males displayed a significantly lower $(P<0.05)$ barnacle abundance in the offshore area during autumn. The north Moreton Bay area had the only significant difference within a season, with males having significantly higher $(P<0.05)$ barnacle abundances. Females sampled in autumn displayed significantly higher abundances in the north Moreton Bay area and males showed significantly lower $(P<0.05)$ mean abundances during winter. Again it must be noted that this sample was obtained using trawl gear rather than baited pots. All other differences within each season were non-significant. The high variation within each season precludes the detection of any significant differences between seasons.

\section{Influence of Sacculina granifera on infestation by other barnacles}

Seventy-seven (12.3\%) of the crabs examined were parasitised by the rhizocephalan Sacculina granifera. These crabs
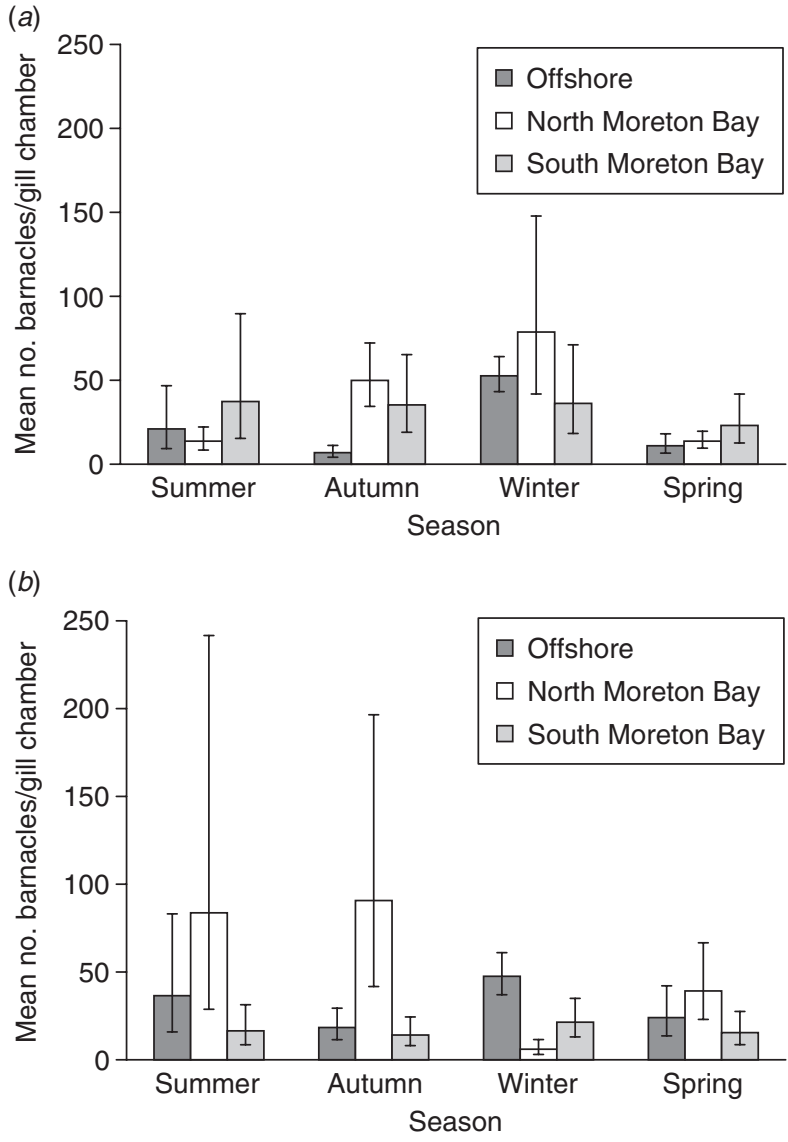

Fig. 7. Model predictions ( \pm s.e.m.) of the spatial and temporal variation in adult Octolasmis spp. prevalence on $(a)$ male and $(b)$ female Portunus pelagicus in the three areas.

were analysed to determine the effects of $S$. granifera on the abundance of other barnacle epizoites. Due to the lack of $S$. granifera infested crabs in offshore samples, only the crabs from north and south Moreton Bay were included in the analysis. Season was not considered as a factor in the analysis as parasitism by $S$. granifera was not represented across 
Table 5. Results of a generalised linear model analysing the effect of various factors on the prevalence of recently settled and adult Octolasmis spp. in branchial chambers of crabs parasitised by Sacculina granifera

\begin{tabular}{lcr}
\hline Factor & Recently settled & Adult \\
\hline Area & $<0.001$ & 0.005 \\
Sex & 0.503 & 0.169 \\
Saccullina granifera & 0.03 & $<0.001$ \\
Area $\times$ sex & 0.047 & 0.593 \\
Area $\times$ Sacculina granifera & 0.904 & 0.096 \\
Sex $\times$ Sacculina granifera & 0.021 & 0.003 \\
Area $\times$ sex $\times$ Sacculina granifera & 0.001 & 0.738 \\
Carapace width (covariate) & 0.029 & 0.026 \\
\hline
\end{tabular}

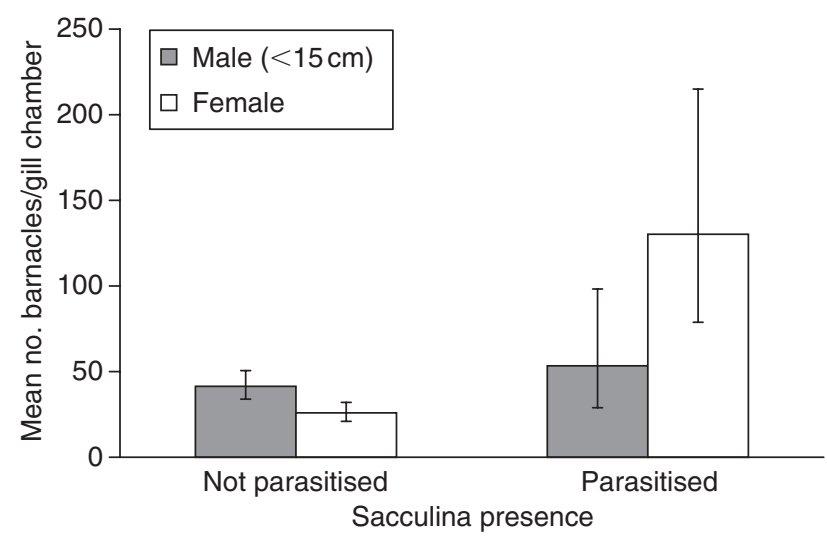

Fig. 8. Model predictions of the prevalence ( \pm s.e.m.) of adult Octolasmis spp. in gill chambers of intermoult male and female Portunus pelagicus infested with Sacculina granifera.

all seasons and areas. The statistical significances of factors from the GLM for recently settled and adult octolasmids are shown in Table 5. As with previous analyses a significant relationship between carapace width and barnacle abundance exists. A significant three-way interaction between area, sex and $S$. granifera presence existed for recently settled octolasmids, with a two-way interaction between sex and $S$. granifera presence for adult octolasmids.

Males not parasitised by $S$. granifera displayed significantly higher adult barnacle abundances than females with 41.4 (95\%C.I. 50.5-33.8) and 25.9 (95\%C.I. 32.0-20.9) barnacles per gill chamber, respectively (Fig. 8). Differences between parasitised and non-parasitised females were non-significant $(P>0.05)$. Parasitised females showed the highest adult barnacle abundances with significantly higher $(P<0.001)$ barnacle loads than both sexes unparasitised by $S$. granifera (130.0, 95\%C.I. 214.9-78.8 barnacles per gill chamber)

Females in south Moreton Bay exhibited the only significant difference $(P<0.001)$ between parasitised and unparasitised crabs from the same area (Fig. 9). Parasitised females

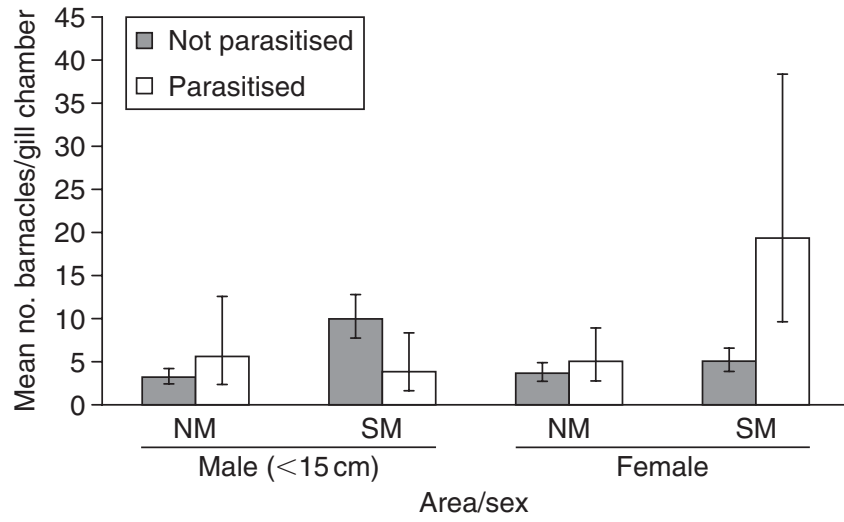

Fig. 9. Model predictions of the spatial variation in the prevalence ( \pm s.e.m.) of recently settled Octolasmis spp. in gill chambers of parasitised and non-parasitised Portunus pelagicus. NM, northern Moreton Bay; SM, southern Moreton Bay.

in this area had significantly higher recently settled Octolasmis spp. loads at 19.3 (95\%C.I. 38.4-9.7) barnacles per gill chamber compared with a mean of 5.1 (95\%C.I. 6.6-3.9) for unparasitised females.

\section{Discussion}

The blue swimmer crab, Portunus pelagicus, from areas around Moreton Bay displayed a markedly higher prevalence $(92 \%)$ of Octolasmis spp. than the rates reported by Gannon (1990) for the blue crab Callinectes sapidus (40\%), Shields (1992) for P. pelagicus (70.2\%) and Walker (2001) for the swimming crab Charybdis callianassa (63.5\%). Portunus pelagicus exhibited comparable distributions within crabs to those reported for C. sapidus by Walker (1974) and Jeffries and Voris (1983). In the present study Octolasmis spp. settled in a non-random fashion and were more likely to settle in ventilated locations. In P. pelagicus, as with $C$. sapidus higher concentrations were found on gills 3, 4 and 5. The proximal surfaces of the hypobranchial side of each gill displayed the highest concentration of barnacles, with the distal surfaces on the hyperbranchial side having the lowest settlement. This distribution correlates well to the ventilatory flow through the branchial chamber. On entering the inhalant aperture, the water generally takes a U-shaped route through the branchial chamber. This route starts at the inhalant aperture, moves posteriorly into the hypobranchial part of the chamber, then dorsally between the gill lamellae. Exhalent current flows anteriorly in the dorsal area of the branchial chamber to the exhalent aperture (Barnes 1974).

The distribution of Octolasmis spp. in the branchial chambers of $P$. pelagicus is similar to that found in the blue crab C. sapidus by Walker (1974). However, P. pelagicus displayed a higher relative frequency on gills 1 and 2, with $10.9 \%$ and $12.8 \%$, respectively. This can be explained when one considers that Walker (1974) only included the barnacles on the 
ventral side of the gills. Walker (1974) states that due to the close apposition of gills, cypris larvae are unlikely to be able to pass through the lamellae of the gills to the hyperbranchial side. Settlement on the hyperbranchial side of the gills can therefore only occur when respiratory flow is reversed. Reversal of flow is thought to occur during and after burrowing as a means of cleaning the gills and branchial chamber (Barnes 1974).

The moult stage of crabs displayed trends of higher abundances in later moult stages similar to that found by Shields (1992); however, in contrast with the results of Santos and Bueno (2001) who found that the prevalence of the nemertean Carcinonemertes carcinophila imminuta did not differ with the moult stages of the Callinectes denae or Callinectes ornatus. The low number of crabs representing several moult stages in the present study precludes any conclusions being drawn, although the presence of both juvenile and adult Octolasmis spp. in post-moult crabs indicates intermittent settlement and rapid growth rate of the epizoites.

The epizoites Chelonibia patula and $O$. warwickii were found to select the same hosts as the Octolasmis spp. found in the branchial chamber. These three epizoites do not share the same microhabitat, with $C$. patula and $O$. warwickii settling only on the external surfaces. Gannon (1990) identified four mechanisms that would make a crab an ideal host and possibly result in the co-occurrence of these species. Infrequent moulting of the host; greater settlement area of the host; reduced resistance of the host to harmful effects after settlement by one species; and the planktonic larvae of the barnacle species completing development and settling in the same areas. It is unlikely that settlement by an external barnacle would result in a reduced resistance to settlement by Octolasmis spp. Infrequent moulting and greater settlement area cannot be treated as separate functions as they display a large degree of co-linearity with larger crabs, which are observed as having longer intermoult periods, thus moulting less frequently (Sumpton et al. 1994b). The co-occurrence of these species is most likely a function of host size and the larval ecology of the barnacle species. The varied nature of host activity would account for settlement of larvae from more than one species; however, it is improbable that the larvae complete development and settle in the same areas.

The abundance of Octolasmis spp. per branchial chamber displayed a marked spatial distribution. The offshore area was found to have significantly higher barnacle loads in all seasons for both sexes. This trend was only evident for newly settled octolasmids, with adult octolasmids not showing any marked patterns relating to area, season or sex. The lack of any clear pattern with respect to the adult octolasmids is perhaps due to the fact that only crabs with longer intermoult periods are likely to have high loads of adult epizoites.

An infestation rate of $12 \%$ for Sacculina granifera was consistent with Shields (1992) and comparable with
Sumpton et al. (1994a) who found an infestation rate of $7 \%$ in males and $12.3 \%$ in females. The nature of $S$. granifera whose infection inhibits moulting in $P$. pelagicus (Phillips and Cannon 1978), subsequently increases the intermoult period, making infected crabs an ideal host for epizoic barnacles. In the present study only female crabs infected by $S$. granifera exhibited higher barnacle abundances. This higher barnacle abundance for females parasitised by $S$. granifera may reflect the different habitat preferences of females (Sumpton et al. 1989). These results contrast with those of Phillips and Cannon (1978), who found noticeably more thoracican barnacles and slightly more stalked barnacles in crabs infected by $S$. granifera.

The effects of infestation by Octolasmis muelleri on gas exchange in the blue crab Callinectes sapidus was assessed by Gannon and Wheatly (1992) who found that high infestation rates caused physiological stress on the host. Crabs with massive infestation did not survive the stress of experimental handling and displayed a higher incidence of experimental mortality when subjected to aerial exposure and elevated temperatures (Gannon and Wheatly 1988). The prevalence of Octolasmis spp. in the present study is higher than that found by Shields (1992). Shields (1992) found a 70.2\% prevalence of Octolasmis spp. for crabs captured exclusively in the area adjacent to the north Moreton Bay region sampled in this study. Gannon (1990) found infestation numbers of between 0 and 224 for $O$. muelleri, and described heavy infestation as greater than 50 barnacles per crab. This contrasts with the present study in which over $64 \%$ of the crabs had more than 50 barnacles per crab ( 25 per branchial chamber). Although the present study used larger experimental crabs than Gannon (1990), the high barnacle load of P. pelagicus may potentially cause high mortality for crabs that are stressed in other ways. This could be particularly relevant for commercially caught crabs with heavy barnacle loads. Such crabs that are stressed during handling may suffer high rates of post-discard mortality thereby adversely impacting on the fishery.

Despite the negative consequences of infestation by barnacle epizoites, the parasites and epizoites of crab populations may have potential application as biological tags for use in stock discrimination. This method of stock discrimination is particularly suited to crustaceans where artificial tags can potentially alter the behaviour of artificially tagged hosts and are difficult to use due to moulting (MacKenzie and Abaunza 1998). Octolasmis spp. may be particularly suited as a biological tag for $P$. pelagicus because of the relatively short intermoult period and the apparent high prevalence of the epizoite in some areas. However, based on the results of this study, the potential for using epizoite load for stock discrimination in P. pelagicus is somewhat limited. The differences observed between offshore and Moreton Bay areas were significant, however, the within-area variance was high, reducing the accuracy of any predictions made. Any further 
work in this area should consider the species composition between the areas, with at least five species from the genus Octolasmis known to settle on P. pelagicus (Jeffries et al. 1982).

\section{References}

Barnes, R. D. (1974). 'Invertebrate Zoology.' (WB Saunders: Philadelphia, PA, USA.)

Bishop, R. K., and Cannon, L. R. G. (1979). Morbid behaviour of the commercial sand crab, Portunus pelagicus (L.), parasitised by Sacculina granifera Boschma, 1973 (Cirripedia : Rhizocephala). Journal of Fish Diseases 2, 131-144.

Drach, P. (1939). Mue et cycle d'entermue chez les Crustacès Décapodes. Annales de l'Institut Oceanographique 19, 109-391.

Gannon, A. T. (1990). Distribution of Octolasmis muelleri, an ectocommensal gill barnacle, on the blue crab. Bulletin of Marine Science 46, 55-61.

Gannon, A. T., and Wheatly, M. G. (1988). Physiological effects of an ectocommensal gill barnacle on blue crabs. American Zoologist 28, 85A. [Abstract]

Gannon, A. T., and Wheatly, M. G. (1992). Physiological effects of an ectocommensal gill barnacle, Octolasmis muelleri, on gas exchange in the blue crab Callinectes sapidus. Journal of Crustacean Biology 12, 11-18.

Gannon, A. T., and Wheatly, M. G. (1995). Physiological effects of a gill barnacle on host blue crabs during short-term exercise and recovery. Marine Behaviour and Physiology 24, 215-225.

Jeffries, W. B., and Voris, H. K. (1983). The distribution, size and reproduction of the pedunculate barnacle Octolasmis muelleri (Coker 1902), on the blue crab, Callinectes sapidus (Rathbun 1896). Fieldiana-Zoology 16, 1-10.

Jeffries, W. B., and Voris, H. K. (1996). A subject indexed bibliography of the symbiotic barnacles of the genus Octolasmis Gray, 1825 (Crustacea:Cirripedia: Poecilasmatidae). The Raffles Bulletin of Zoology 44(2), 575-592.

Jeffries, W. B., Voris, H. K., and Poovachiranon, S. (1992). Age of the mangrove crab Scylla serrata at colonisation by stalked barnacles of the genus Octolasmis. The Biological Bulletin 182, 182-194.

Jeffries, W. B., Voris, H. K., and Yang, C. M. (1982). Diversity and distribution of the pedunculate barnacle Octolasmis in the seas adjacent to Singapore. Journal of Crustacean Biology 2, 562-569.

Key, M. M., Volpe, J. W., Jeffries, W. B., and Voris, H. K. (1997). Barnacle fouling of the blue crab Callinectes sapidus at Beaufort, North Carolina. Journal of Crustacean Biology 17, 424-439.

Kendall, M., Stuart, A. and Ord, J. K. (1983). 'The Advanced Theory of Statistics. Vol. 3.' 4th Edn. (Griffin: London, UK.)

Lyle, W. G., and MacDonald, C. D. (1983). Moult stage determination in the Hawaiian spiny lobster Panulirus marginatus. Journal of Crustacean Biology 3, 208-216.

MacKenzie, K., and Abaunza, P. (1998). Parasites as biological tags for stock discrimination of marine fish: a guide to procedures and methods. Fisheries Research 38, 45-56. doi:10.1016/S01657836(98)00116-7

Phillips, W. J., and Cannon, L. R. G. (1978). Ecological observations on the commercial sand crab, Portunus pelagicus (L.) and its parasite,
Sacculina granifera Boschma, 1973 (Cirripedia:Rhizocephala). Journal of Fish Diseases 1, 137-149.

Santos, C., and Bueno, S. L. (2001). Prevalence and mean intensity of infestation by Carcinonemertes carcinophila imminuta (Nemertea : Carcinonemertidae) in the gills of Callinectes danae and Callinectes ornatus (Decapoda: Portunidae) from Sao Sebastiao, Brazil. Hydrobiologia 456, 65-71. doi:10.1023/A:1013059310936

Shields, J. D. (1992). Parasites and epizoites of the crab Portunus pelagicus from Moreton Bay, Eastern Australia. Journal of Crustacean Biology 12, 94-100.

Shields, J. D., and Wood, F. E. (1993). Impact of parasites on the reproduction and fecundity of the blue sand crab Portunus pelagicus from Moreton Bay, Australia. Marine Ecology Progress Series 92, 159-170.

Smith, L. D., and Hines, A. H. (1991). Autotomy in the blue crab (Callinectes sapidus Rathbun) populations: geographic, temporal and ontogenetic variation. The Biological Bulletin 180, 416-431.

Sumpton, W. D., Gaddes, S. W., and Mclennan, M. (2000). 'Blue Swimmer Crab fishery in Queensland: Summary of changes 1984-1998.' Queensland Department of Primary Industries Report Series QO00009. (Queensland Department of Primary Industries: Brisbane, Australia.)

Sumpton, W. D., Potter, M. A., and Smith, G. S. (1989). The commercial pot and trawl fisheries for sand crabs (Portunus pelagicus L.) in Moreton Bay, Queensland. Proceedings of the Royal Society of Queensland 100, 89-100.

Sumpton, W. D., Potter, M. A., and Smith, G. S. (1994a). Parasitism of the commercial Sand Crab Portunus pelagicus (L.) by the rhizocephalan Sacculina granifera Boschma, 1973 in Moreton Bay, Queensland, Australia. Australian Journal of Marine and Freshwater Research 45, 169-175.

Sumpton, W. D., Potter, M. A., and Smith, G. S. (1994b). Reproduction and growth of the commercial sand crab, Portunus pelagicus (L.) in Moreton Bay, Queensland. Asian Fisheries Science 7, 103-113.

Thomson, J. M. (1951). Catch composition of the sand crab fishery in Moreton Bay. Australian Journal of Marine and Freshwater Research 2, 237-244.

Van Engel, W. A. (1958). The blue crab and its fishery in Chesapeake Bay. I. Reproduction, early development, growth and migration. Commercial Fisheries Review 20, 6-17.

Walker, G. (1974). The occurrence, distribution and attachment of the pedunculate barnacle Octolasmis mulleri (Coker) on the gills of crabs, particularly the blue crab, Callinectes sapidus Rathbun. The Biological Bulletin 147, 678-689.

Walker, G. (2001). Some observations on the epizoic barnacle Octolasmis angulata within the branchial chambers of an Australian swimming crab. Journal of Crustacean Biology 21(2), 450-455

Weng, H. T. (1987). The parasitic barnacle Sacculina granifera Boschma, affecting the commercial sand crab Portunus pelagicus (L.), in two different environments in Queensland. Journal of Fish Diseases 10, 221-227.

Manuscript received 14 October 2002; revised 26 February 2004; and accepted 12 March 2004 